\title{
Analysis and Management Initiatives for College Students' Pressure
}

\author{
Zhiyuan LI \\ School of Managment, Harbin University of Science and Technology, Harbin 150000, China
}

\begin{abstract}
In this study, the psychology of contemporary college students is analyzed from various perspective, their pressure constitute is fully explained. They experience a variety of pressure, for example, different understanding, study pressure, life pressure understanding, emotional pressure, career pressure. After that, the related solutions are proposed. It starts from the source to explore the method to solve the problem. Therefore, the universities can take the appropriate measures to achieve the ideal mental health education.
\end{abstract}

KEYWORD: Analysis; Pressure factors; Measures; College students

\section{INTRODUCTION}

In recent years, the regretful and distraught cases of China's college students' suicide or depression are frequently broadcast. However, where does he psychological pressure of the contemporary college students come from? What does our education have to do with this phenomenon? What is the role of colleges in this circumstance? All these issues deserve our deep thinking. China's education is not just about knowledge; what's more important is mental health training because students' psychological health is directly connected to the level of education. Therefore, not only students' test scores but also the students' mental health should be very important measures[1]. And we need to deal with these problems through higher education.

Therefore, we need to understand the psychological pressure sources of college students and what makes the college students' mental capacity so low and vulnerable. According to China's current social situation, college students, as a special group who accept a higher level of education than average, have a lot more pressure than others. Moreover, college students have a very high self or otheroriented expectations. But college students generally have the ideal understanding of the society and lack of social experiences. Thus, they are prone to face different pressurees in their emotions, life, employment, communication and other aspects which have been plaguing them in the life and study. A detailed analysis is conducted as follows.

\section{FACTORS OF PRESSURE}

\subsection{Different understanding}

As each student enters college and all the environments change, he will have a psychological transformation and adaptation, referred as "Freshman Mental Imbalance", which is caused by many reasons. First of all, there is a large gap between the reality of the university between their imagination. Many college students know their schools through media and once they enter the university, the real situation and the environment cause a psychological gap and a strong psychological imbalance. Secondly, after entering college, freshmen's learning environment, living environment and relationships change. In the environment of the university, they are no longer the top students or the best. They have to start from the very beginning for the glory; all the relationships must be built from the very beginning. Freshmen get confused at all these problems which induce psychological imbalance.

\subsection{Study pressure}

The eager attitude of parents bring their children a lot of tangible and intangible pressure. In particular, the children from those families in relatively financial difficulty have pressure several times higher than others. Plus, all the students have gone through the harsh college entrance examination and they get used to the forced learning methods in high school, thus become completely lost at the independent learning method. Moreover, the university, as a special social environment, assesses 
a student not only merely based on their academic performance, but also their full development, including the high demands of students' social communication capacity. Therefore, the students who are only good at learning will easily get a sense of loss. In addition, some students who don't do well at the college entrance exam are rarely able to choose their favorite professional. Even worse, some students do not even know what is researched in their professional. As an investigation showed, 75\% students chose their professional out of their own intentions. As a result of such a high proportion, a lot of students can not adjust their feelings because of the deviations from their expection of the college. Many students have a contradiction and have no passion to learn, which causes low scores. Suffering long-term unaccomplished self-worth, the pressure on the learning is natural and unavoidable.

\subsection{Life pressure understanding}

First, a large part of the pressure is due to the lack of living skills in the new environment. When they enter college, a completely independent environment, they have to be completely on their own, so it is easy to produce maladaptive psychology. They can not get it right from the original psychological dependence because they are accustomed to the pattern that someone else will show up and solve the problem for them. But all of sudden, the new environment makes them fully independent and fully grown, which is unlikely to happen overnight. They need an adjusting process while quite often in this process, the freshmen face many failures because of their inadequate capacity and self-perception. Afterwards, they have a deep sense of loneliness and fear, and slowly it is converted to psychological problems. In addition, a major factor that generates their psychological pressure lies in the interpersonal discord. With the change in their living environment, their relationships change, too. Freshmen have to stay away from the original living environment, the original family and friends and live in a completely strange living environment, where the student's family background, learning environment, hobbies, character and capability can become a topic or concern to others. At the same time, the concern of and from others will inevitably produce psychological comparisons. That is, every word or move of them could become someone else's laughing topic. Therefore, a lot of students refuse to talk after they enter the university, and slowly form a relatively autistic character. Or some students become too strong to be suited in a group, resulting in their isolation. Then they gradually deny and suspect themselves psychologically; they can not find a suitable method to communicate with others, can not run in healthy relationships in the new environment. It's reported that the dormitory relationship has become a psychological disorder which is at the same level of pressure contributed by the factors associated with learning.

\subsection{Emotional pressure}

College students are in late adolescence where their physical development has already matured and begin to desire the opposite sex. However, in the pursuit of the opposite sex, because they have no experience with the opposite sex, they often have to face this or that problem that they have not experienced before and they are unable to solve. Therefore, a lot of people use the wrong method to solve their emotional problems. Contemporary college students are young and have little experience, relatively easy impulsiveness, and large emotional volatility. Especially when they leave their homes to get into a new environment, the sense of loneliness and fear more than likely inspire their desire for the opposite sex. When they fall in love, many students put their lovers in the first place, which also makes them neglect other emotions, such as family or friendship. However, once their relationship with their boyfriend or girlfriend ends, they will feel that the focus of life totally collapses and it is meaningless to go on with their life. Some students will therefore have a very extreme, which causes disfigurement, suicide tragedy one after another; they are anxious, inconfident or morbid caused by emotional crisis.

\subsection{Career pressure}

In modern times, the difficult situation of the unemployment of college graduates has become a well-known problem. Until 2013, China's college graduates have amounted to 6.99 million, the largest since the founding of P.R. China. The employment pressure on college students is obvious, so the graduating students who are under this strong competitiveness are anxious about the future social life. The sense of uncertainty will be more intense because they do not know where their future lives will go. Nowadays, China's national conditions make graduates less demanded by society. The companies generally prefer the candidates with work experience in the interview, which makes it very difficult for the newly graduated. Only a few very outstanding students are not troubled by the unemployment while most of the rest have no experience in the society. They are in the face of the upcoming life and will have a lot of psychological problems, like fear, anxiety and sense of loss. When their resume gets refused, they doubt their ability. Of course, many students choose to continue their studies and continue to learn one way or the other to avoid the difficult students' unemployment boom, but no one can guarantee that further studies can improve the 
difficult unemployment situation; some college students are looking forward to graduation because they feel they can finally enter the society to work and achieve their value of life. But no matter which way they choose, there are so many uncertainties. They are afraid of the corrupted social atmosphere, the complex relationships, their own unknown future, so in this ongoing unrest, they are very easy to develop a psychological problem.

\section{CORRESPONDENT INITIATIVES OF COLLEGES}

We analyze the causes of college students' psychological pressure. If they can not get the right guidance and timely resolve these emotions, they are bound to have an impact on their lives and work, resulting in their extremism in their future. Based on the analysis above, the China's colleges and universities should take the following measures.

\subsection{Establishment and Improvement of Healthy Educational Philosophy in Colleges}

Many people nowadays believe that only students' achievements can reflect the college level. But in fact, college students mental health scores should also serve as an important measure. Mental health education, as an important course, should be a priority in imparting knowledge[2]. Furthermore, different educational contents should be prepared at different stages so that each student can personally experience the importance of mental health education all the time. While carrying out mental health education, colleges should also improve their own environment. It is known that people can be calm in the beautiful environment. If a college pays attention to the mental health education, the college students will put their emphasis on the importance of this work. And they will deeply understand the importance of the mental health education through the vital campus scene. Gradually, the mental health concern will slowly be merged into their life. As long as the college and the students can correctly treat mental health education, our harmonious society can be built soon, which in return, as a huge role in catalysis and cohesion, can develop excellent psychological quality of college students.

\subsection{Comprehensive Team of Highly Qualified Educators}

Mental health education is a system, which is not limited to college students, so we should start the education from an early age through various means. While we improve the awareness of college students' mental health education, we also should set up a comprehensive, high-quality teacher group to help students overcome psychological problems and the blind spot and help them to get out of the negative spiritual world as soon as possible so as to rebuild positive attitude to social life and to improve their ability to withstand pressure. These are urgent needs for us to do. Meanwhile, the college teachers should also help mental health educators to ensure that they play a significant role[3]. Due to the fact that their growing environment and their own personality are quite different, the situation of college students' psychological imbalance is manifested. Teachers, while teaching knowledge, should also simultaneously spread the knowledge of psychological health so that the students can know about the mental health in their daily life. And they will realize that the psychological problems are not abnormal, which can be adjusted in the early stages. Thus, the psychological teacher can propose solutions based on real problems to play his due role.

\subsection{Various Opportunities for College Students to Participate in Social Practices}

After we emphasize the importance of mental health education in many ways, the practice has become the last step of the mental health education. After we completely aware the mental health education, we need time to test the outcomes of our mental health education. This time, we need universities to play its due role; we need colleges to provide community practice opportunities for contemporary college students so that they can deeply understand the mental health education and the solution to some simple psychological problems through practice. As the saying goes, travelling ten thousand li is more eye-opening than reading ten thousand books[4]. Through the knowledge taught by the teachers and the textbooks only, college students can not understand the real world and combine it with the knowledge. Therefore, it is impossible for them to solve the problem thoroughly. Only through practice, can they truly understand the psychological health education, develop their proper psychological concepts and better serve the nation.

\section{SUMMARY}

Colleges and universities are supposed to combine the mental health education and the practical problems in the above three methods and solve the fundamental psychological problems for college students so that they can establish a good psychological quality without cowardliness, extreme or unhealthy ways to solve the problems. This desired effect can be achieved only through the attention of universities and the strive of teachers and students[5]. Colleges should not only teach students knowledge but also improve their quality, 
develop their independence, and improve their ability to withstand pressure so as to adjust for the future social life without the fear of any difficulties, the unrest of any changes in the environment, or the psychological rely to solve problems independently. Through the joint efforts of universities and students, the current situation of college students' pressure can be improved radically in order to cultivate a generation with superior quality and healthy mental.

\section{REFERENCES}

[1] Psychological pressure of college students and correspondent strategies. Social Science Teaching Department of Suzhou Institute. 2005.
[2] Features of Network-Based Mental Health Education in Colleges and Universities from the Perspective of Constructivism. Scientific Research Publishing. 2011:3.

[3] Creating a scale to measure motivation to achieve academically: Linking attitudes and behaviours using Rasch measurement. British Journal of Educational Psychology. 2010 (1).

[4] Financing Higher Education: Lessons from Economic Theory and Reform in England. Higher Education in Europe. 2009 (2).

[5] Conventional Fixed-schedule versus Income Contingent Repayment Obligations: Is There a Best Loan Scheme. Higher Education in Europe. 2009 (2). 